\title{
AOR
}

Selected Papers of \#AolR2020:

The $21^{\text {st }}$ Annual Conference of the

Association of Internet Researchers

Virtual Event / 27-31 October 2020

\section{AGEING WITH SMARTPHONES 'FROM BELOW': INSIGHTS FROM JAPAN, UGANDA, AL-QUDS AND IRELAND}

\author{
Laura Happio-Kirk \\ University College London \\ Charlotte Hawkins \\ University College London \\ Maya de Vries-Kedem \\ Hebrew University of Jerusalem \\ Daniel Miller \\ University College London
}

This session examines new ways to theorize the smartphone, based on a comparative study of smartphone use amongst older people in four different fieldsites for a period of 16 months ethnographic fieldwork.

Along with gender, age is one of the primary parameters by which societies throughout history have structured and governed themselves (Spencer, 1990). Since the 1960s, however, we have lived with an unprecedented modern consciousness that has presented an increasingly powerful challenge to this hegemonic principle by placing a high value on youth culture (Hodkinson, 1999). As a result, there is a new uncertainty about the meaning of age (Degnen, 2007). In addition, age has also extended class discrepancies, as those around the world between the ages of 45-70 have become a class that has settled its children and can now capitalize upon the new choices of consumer culture (Blaikie, 1999). Yet, these ageing populations increasingly face problems of loneliness linked to a loss of authority of seniority (Hazan, 1994), though this may be alleviated by contact through digital devices and networked platforms, mainly smartphones.

Focusing on populations in their sixties, seventies and eighties is one of the panel's major contributions, as mostly up until now smartphones have been associated with the idea of a youth technology and many of their attributes associated with that age group

Suggested Citation (APA): Happio-Kirk,L. Hawkins, C., de Vries-Kedem, M., Miller, D. (2020, October). Ageing with Smartphones 'From Below': Insights From Japan, Uganda, Al-Quds and Ireland. Panel presented at AolR 2020: The 21 $1^{\text {th }}$ Annual Conference of the Association of Internet Researchers. Virtual Event: AolR. Retrieved from http://spir.aoir.org. 
(Jenkins et al., 2016). Hence, we wish to release the smartphone from its earlier connections, allowing us to theorise it more broadly as part of the life of 'non-digital natives'.

The four papers in the panel show how understanding smartphones is more than simply addressing the culture of 'apps' or the 'culture of connectivity'. Rather, the smartphone presents an ecology of digitization tailored to the specific configurations of the individual user which is best understood through the ethnographic method of holistic contextualization. This approach links smartphone usage with all aspects of offline life and creates a role for digital anthropologists who are well placed to tackle fundamental questions about smartphones because they can gain access to this intimate and mainly private configuration and processes of personalization within their social and cultural contexts. Using Pype's (2019) concept of 'smart from below' we provide illustrations showing how it is the users who actually create smartphones.

To follow normative contemporary theory, this would require situating our findings in relation to established theoretical debates about new communications media. The nuance given by comparing four fieldsites with a vast variety of smartphone usage ties us to the initial context of difference and comparison, thus providing novel conceptualizations of the smartphone. These include concepts such as 'screen ecology', 'the transportal home', 'beyond anthropomorphism', 'social ecology', 'perpetual opportunism', 'contradiction and ambivalence', 'the control hub', 'multifaceted connectivity' and others. Each of these may help us to visualise, understand, and explain what people do with their smartphones and why. But where this subsumes Uganda, al-Quds, alongside Japan and Ireland there is a danger of creating neoimperial homogenisations based on citing de-contextualised critiques. Our panel strives to describes an alternative path that could allow for theoretical development of the contemporary smartphone, while avoiding these betrayals of either substance or original insight.

Three papers provide more extended examples of what we have achieved 'the transportal home' through fieldwork in Japan, 'care transcending distance' through fieldwork in Uganda, and we explore 'contradiction, ambivalence and multifaceted connectivity' though fieldwork in al-Quds. The fourth paper is more theoretical, aiming to link between the presented ethnographies and exemplify the grounding of theory of the smartphone. We hope that our panel will encourage global discussion of the role of the smartphones in the everyday lives of individuals from all age groups, not just the young. Such an expansion would allow for a deeper understanding of this device which, as we demonstrate, is so central to many people's experience of social life, home, and care.

\section{References}

Blaikie, A. (1999). Ageing and popular culture. Cambridge University Press.

Degnen, C. (2007). Minding the gap: The construction of old age and oldness amongst peers. Journal of Aging Studies, 21(1), 69-80.

Hazan, H., \& Hazzān, H.. (1994). Old age: Constructions and deconstructions. Cambridge University Press. 
Hodkinson, P., \& Bennett, A. (Eds.). (2013). Ageing and youth cultures: Music, style and identity. A\&C Black.

Jenkins, H., Shresthova, S., Gamber-Thompson, L., Kligler-Vilenchik, N., \& Zimmerman, A. (2018). By any media necessary: The new youth activism (Vol. 3). NYU Press.

Pype, K. (2017). Smartness from below: variations on technology and creativity in contemporary Kinshasa. What Do Science, Technology, and Innovation Mean from Africa, 97-115.

Spencer, P. (1990). Anthropology and the Riddle of the Sphinx: Paradoxes of Change in the Life Course. Routledge. 


\title{
A SPATAIL EXPLORATION OF THE SMARTPHONES AS A 'TRANSPORTAL HOME' IN JAPAN
}

\author{
Laura Happio-Kirk \\ University College London
}

This paper elaborates one of the key theoretical outputs of the ERC Anthropology of Smartphones and Smart Ageing project, that the smartphone has become a 'transportal home'. Based on 16 months' ethnography conducted between 2018-2019 in Kyoto city and rural Kōchi Prefecture, Japan, the paper presents the mechanisms by which the smartphone has become the center of many people's lives (chushin), an anchor in a rapidly moving world. The smartphone is argued to be a space for intimacy and care, analogous to Japanese domestic spaces where delineations of the inside/outside (uchi/soto) are negotiated, facilitating the expression of both 'true voice' (honne) and 'public façade' (tatemae).

The ethnographic evidence presented in this paper describes how a sense of alienation and dislocation in the city motivates internal migrants to seek rootedness in rural Japan. However, it is the capacity of the smartphone for connection, intimacy, and selfexpression, that makes the device a space in which 'home' is actually realized. Contemporary modernity is characterized by experiences of rupture and dislocation as movement and relocation have become the norm for many. Indeed, as Said wrote in 1979 , many of us live in "a generalized condition of homelessness" (1979:18), therefore belonging and meaning become sought after in both physical and imagined 'places'. The smartphone is part of a history of technological innovation in which the problem of physical distance has been overcome by virtual and instantaneous connection. This has transformed our experience of space and place and has contributed to the delocalization of identity associated with modernity and globalization (Appadurai, 1996; Gupta \& Ferguson, 1997; Harvey, 1989).

\section{Smartphone as a space for intimacy and care in a time of rupture "I think when we are elderly, it doesn't mean that we have friends right next to us. So the smartphone might feel more precious to us because it allows us to stay sociable." Megumi san is 58 years old and lives in Kyoto. She feels that the smartphone will become increasingly important to her as she ages. Currently, the smartphone helps her to feel close to her friends, even though she does not live near to them. Having her friends always available to message through the application LINE gives her a sense of comfort and strength when dealing with difficult things in her life such as caring for her elderly parents and mother-in-law, or when she became ill with cancer. "I felt that they (my friends) were next to me all the time." For her, the smartphone became a device in which care transcends distance.}


Megumi uses her smartphone to maintain a close and caring relationship with a small group of friends who do not live near to her, making physical proximity irrelevant to their relationship. Many city-center dwellers in Kyoto expressed the view that it is normal in city life to not know your neighbors, and communities are becoming weakened as the city center becomes dominated by the hotel industry. As one Kyoto man in his early eighties said, "All the horizontal relationships are gone now". For some people who are seeking the community they feel is lost in the city, rural towns become representative of an idealised state of community and connection. Many of the recent migrants arriving to rural Kōchi prefecture expressed this search for rootedness and a 'community to lean on' (sasaeru) as a motivating factor for moving to a small rural town. This paper suggests that for both urban-to-rural migrants and city dwellers a sense of rootedness in family and a physical homeland is replaced with rootedness in friendship and digital care which transgresses distance. In this sense, the smartphone can be understood as a 'transportal home'.

\section{Smartphone as 'inside' (Uchi)}

Participants were often reluctant to show the interior of their phone. As one woman explained, "I feel shy about showing people my apps. It's kind of like a bookshelf, it shows my personality. You would only put the covers of the book you want to show in the front too." When considered in relation to the social concepts of inside/outside (uchi/soto) that have been argued to dominate Japanese social interaction (e.g. by Benedict, 1946; Nakane,1970; Doi,1971; Hendry,1995), the smartphone becomes another private territory of which the borders are constantly negotiated. It is helpful here to draw on the analogy of the Japanese home; as Inge Daniels' extensive work (e.g. 2010) on the Japanese domestic space demonstrates, there are features of the traditional Japanese home such as enclosing fences and high walls, frosted glass and barred windows, that are designed to keep the interior private space separate from the public exterior. However, as Daniels (2008) argues, these divisions are not static but are in a constant state of negotiation. Much like with the smartphone where people explore various levels of privacy and exposure to see what feels right. People feel comfortable with a certain degree of intimacy on one app, which may then not be appropriate for a different app. Here the Japanese concepts of honne (true voice) and tatemae (public façade) are useful when discussing how people present different versions of themselves to different audiences.

Participants explained that it is easier to express your real feelings on LINE than on Facebook. Returning to the Japanese home analogy, the safety and privacy afforded by high walls and frosted glass (private or small group messaging) feels more appropriate for sharing real feelings, as opposed to a conversation on the street in public (on Facebook), where potentially anyone can hear. This paper will expand the home analogy to explain for the prevalence of anonymous Twitter and Instagram accounts in Japan. It is through anonymous accounts that people feel they can be the most authentic versions of themselves, where they can express views freely away from the gaze of their peers. In this sense, this is the most private 'room' of the house, where they also experience the most private and interior version of themselves. The smartphone allows people to cultivate 'honne' which can sometimes be difficult to 
articulate, as explained by one woman in her thirties: "for me, honne is like a shadow. You can see the shadow but you can't touch the shadow right? You can feel the honne but you can't actually know it right?"

\section{References}

Appadurai, A. (1996). Modernity at large: cultural dimensions of globalization. Minneapolis: University of Minnesota Press.

Benedict, R. (1946). The Chrysanthemum and the Sword: Patterns of Japanese Culture. Boston: Mariner (Houghton Mifflin).

Daniels, I. (2008). Japanese Homes Inside Out. Home Cultures. 5(2),115-40.

Daniels, I. (2010). The Japanese House: Material Culture in the Modern Home. Oxford: Bloomsbury.

Doi, T. (1971). Amae no kōzō [The Anatomy of Dependence]. Tokyo: Kodansha.

Fielding, A. J., \& Ishikawa, Y. 2003. Migration and the life course in contemporary Japan. Geographical Review of Japan, 76(12), 882-893.

Gupta, A. \& Ferguson, J. (1997). Culture, power and place: explorations in critical anthropology. Durham, N.C.: Duke University Press.

Hendry, J. (1995). Understanding Japanese Society. London: Routledge.

Harvey, D. 1989. The conditions of post-modernity: an inquiry into the conditions of social change. Oxford: Basil Blackwell.

Nakane, C. 1970. Japanese Society. New York, NY: Penguin Books. 


\title{
TAXING CARE: EXPOSING MORAL ECONOMIES IN KAMPALA, UGANDA
}

\author{
Charlotte Hawkins \\ University College London
}

\begin{abstract}
Mobile money is used almost universally by older participants in Kampala, Uganda. This practice is embedded in daily life, often to support older relative's health demonstrating how 'care transcends distance'. In this way, it provides a platform to uphold intergenerational obligation, despite displacement and urbanization, and widespread fears around the increasing selfishness of the 'dotcom generation'. Mobile money has been widely lauded as a bottom-up adaptation of technology to African requirements, offering flexibility, particularly for "the unbanked" (Kusimba et al., 2016: 266; Maurer, 2012: 589). However, the recent imposition of additional levies on mobile money by the Ugandan government offers a lens onto social practices, experiences and hierarchies surrounding mobile money transfers (Maurer, 2016: 312). It shows how the digital is embedded within and across blurred personal lives, moral economies and power structures, and thus what it exposes ethnographically. Drawing on 16 months ethnographic research, this paper traces digital trajectories, specifically mobile money transfers, as they traverse a range of material and political processes, along moral lines, and between the city and the village.
\end{abstract}

In the Ugandan context, money may not equal communication or care, but it is a central element of it (Livingston, 2003). As Edgar, a 67-year-old from Kampala, explained:

Sickness just comes by coincidence, sometimes abruptly when you're not even prepared, you need money to take care of that. So if any sickness, you just have to begin to look around, call a family meeting for any contribution for treatment, "this one has a problem, we need to...", so we help each other like that.

Alongside regular communication and visitation of older relatives, remittances themselves can be conceived as a 'care currency' (Singh et al., 2010). I often saw how Edgar and his children were called upon to support their relatives at home in the village in Palabek, particularly their Jajja (grandmother). They would send food and mobile money during increasingly unpredictable dry seasons. Edgar would visit regularly to check on the land and his mother's health, with his children often funding his transport.

The mobile money transfer invokes multiple social processes, often precipitated with the 'beep' or phone call to make the request from the village. This motivates a decision- 
making process of the potential sender in the city, along moral and financial lines. Is the request worthy? Was it made at the right time by the right person in the right way? Does my pocket stretch far enough beyond immediate family concerns? Can I refuse? In some cases, as Edgar explains, a request is followed with fundraising. Once the cash is collected, the sender will visit the vendor, of which there are as many as 33 in the fieldsite alone. The money is sent via SMS by the vendor on their mobile phone. The recipient will then receive notice of the transfer via SMS and will travel to their nearest vendor who helps them to collect the money. This can require travel over long distances in rural areas - in Edgars' home village in rural Northern Uganda, it could take over 2 hours to the nearest trading center by foot. Sometimes, the money is transferred or delivered further along a chain of relatives, depending who has been trusted with the money or who has the access and capacity (digital and physical) to do so.

Various participants explained how they provide for their parents and relatives in the village without visiting them as "you can send money on the phone". In a survey of 50 older participants phone use in September 2018, 47 had used mobile money in the previous month. The greatest proportion of the 130 recorded remittances, $25 \%$ were for health purposes, which could include hospital bills, medicine and transport to hospital. 6 of these transfers were received or forwarded by the respondent in a chain of remittances, for the purposes of supporting older relatives. For example, one respondent had received 200,000 UGX (Uganda currency) from her daughter, in order to help her take her mother in the village to hospital; or another who received 30,000 from their Aunt for their grandmother's hospital bills, who did not have a mobile phone herself.

In June 2018, a mobile money tax was introduced, including an additional levy of $1 \%$ on deposit and withdrawal, later reduced to $0.5 \%{ }^{1}$. At the time, the Uganda Communications Commission (UCC) found that people's mobile money balances significantly dropped at a national level ${ }^{2}$, with many mobile money vendors in Go-down reporting that they had $30 \%$ fewer customers each month. Some of them found that people were using different means to transport money, including boarding the 12-hour bus to transport larger sums if the fare was cheaper than the tax. 20 survey participants said they had reduced their mobile money use or stopped completely. But the majority said that they still send mobile money in the same way since the imposition of the tax. "It's stressing me but nothing to do". This came as part of a wider crackdown on what the President Museveni termed 'over the top' internet usage, with Uganda controversially becoming the first country to tax social media. The President made an announcement (ironically on Twitter) in which he denigrated the immorality of OTT 'olugambo', malicious gossip and misinformation on social media ${ }^{3}$ and announced a monthly charge of 6,000ush to access Facebook, WhatsApp, Instagram, Twitter, Skype,

\footnotetext{
${ }^{1}$ See President Museveni's announcement on his website: https://www.yowerikmuseveni.com/whygovernment-taxing-social-media-president-museveni , accessed 21.02 .20

${ }^{2}$ https://www.ucc.co.ug/wp-content/uploads/2017/09/UCC-Sector-Report-December-2018 260719.pdf, p.30, accessed 31.07.19

${ }^{3}$ https://www.yowerikmuseveni.com/why-government-taxing-social-media-president-museveni, accessed 21.02.20
} 
Linkedln accounts. This prompted various petitions and protests, including social media campaigns such as \#ThisTaxMustGo.

Ferguson argues that economic measures are often presented and interpreted in moral terms in Africa (Ferguson, 2006). This is evidently true in relation to mobile phone use, primarily a tool for 'care at a distance' and therefore already imbued with cooperative moralities. Some participants advocated for the tax, the contribution to Uganda's budget, and the prevention of useless 'olugambo'. But for others it sharpened a sense of imposition, exclusion or marginality, the tax conceived as an assertion of the state as 'predator' (ibid, 85); this was also the language of protest (Cole \& Durham, $2007: 4$ ). Narratives of political economy in relation to ICTs thus draw on, and exacerbate, the contradictory discourses of fear and opportunity (Miller \& Slater, 2000: 140); in this case, new media is simultaneously an idiom and platform to both support and challenge core moralities (ibid), thereby exposing them for ethnographic analysis.

\section{References}

Cole, J., \& Durham, D. L. (2007). Generations and globalization youth, age, and family in the new world economy.

Kusimba, S., Yang, Y., \& Chawla, N. (2016). Hearthholds of mobile money in western Kenya: Hearthholds of mobile money in western Kenya. Economic Anthropology, 3(2), 266-279. https://doi.org/10.1002/sea2.12055

Livingston, J. (2003). Reconfiguring old age: Elderly women and concerns over care in southeastern Botswana. Medical Anthropology, 22(3), 205-231. https://doi.org/10.1080/01459740306771

Maurer, B. (2012). Mobile Money: Communication, Consumption and Change in the Payments Space. Journal of Development Studies, 48(5), 589-604. https://doi.org/10.1080/00220388.2011.621944

Maurer, B. (2016). Regulation as Retrospective Ethnography. Banking and Finance Law Review, 27, 299-313.

Miller, D., \& Slater, D. (2000). The Internet: An ethnographic approach. Berg. 


\section{AGEING WITH SMARTPHONE IN AL-QUDS: MULTIFACTED CONNETIVITY}

Maya de Vries Kedem

Hebrew University of Jerusalem

Smartphones are one of the most ubiquitous technological devices used in the world today, due to their capacity for use in a vast range of activities (Bitman \& John, 2019; Madianou, 2014). While the concept of Polymedia (Madianou \& Miller, 2013) presupposes factors such as access, cost, and literacy move from the foreground to the background, the case study presented in this paper shows that these factors are still significant, implying that users' feelings and practices of connectivity (Van Dijck, 2013) are multifaceted. It also contributes to the ASSA project's theories of the smartphone concerned with Contradiction and Ambivalence.

This paper is based on a 16 months ethnographic fieldwork (Geertz, 1974) in what we called Dar al-Hawa, a Palestinian neighborhood of 10,000 people in al-Quds ${ }^{4}$, among men and women in their fifties, sixties, and seventies. we investigated fundamental changes in the relationship between people's perception of age, health, digital skills and quality of life as associated with smartphone use.

\section{Routine Connectivity}

Smartphones made communication with their family members (parents, children and grandchildren) easier, whether they were inside or outside the country. Family members living outside of Jerusalem is common as the Palestinian society has a large diaspora in Jordan, Lebanon, USA and Brazil (Palestinian Central Bureau of Statistics report, 2015). Most of the people we met in the fieldsite actively use voice calls, WhatsApp and Facebook Messenger to communicate. Besides catching up with distant family members, they also send each other religious prayers, blessings, and quotes from the Qur'an, some browse, mainly on Facebook, to follow daily news.

However, aligned with Lev-On et al.'s (2019) report about digital inequalities in Israel, this connectivity may be considered rather basic, as none of the participants use their smartphone to pay bills, do online shopping or to set an appointment with the doctor. In this manner the al-Quds fieldsite is quite different when compared to other fieldsites in the ASSA project such as Ireland and Japan. It thus indicates how the smartphone is a

\footnotetext{
${ }^{4} \mathrm{Al}-\mathrm{Quds}$ is the Arabic name for Jerusalem. Since all the informants are Arabs, we decided to use the Arabic name of the city.
} 
cultural tool (Gordon, Al Zidjaly \& Tovares, 2017) that amplifies the user's lack of digital knowledge and in al-Quds its socio-political gaps.

\section{Digital and social illiteracy}

Alongside our projects in Chile and Brazil, my involvement in teaching smartphone use to older people revealed their struggles with this technology including remembering procedures and working with touch screens. The impact of this on digital inequality is argued by Mayar (46):

"I am afraid that a time will come when everything will be online. I do not know how to pay in this way. Sometimes when I am in a car park, I am asked to pay for the space online. I am also afraid that a day will come that I cannot find a machine to pay. That's why I wish to find a class to teach me how to use the smartphone. Girls in their twenties may know how to pay via the internet, but us women over 45 need education in this field."

The fieldwork also demonstrated how digital illiteracy linked to the Hebrew language illiteracy and its connection to digital bureaucracy that is becoming more and more present in our life. Old people in al-Quds who did not learn Hebrew at school will be facing hard time when trying to communicate in some of the new governmental apps. Knowledge of Hebrew is particularly poor for those who had lived on the Jordanian side of the pre-1967 border, and for women who are less likely to have worked within Israel. When looking at people's smartphones and asking which apps they use, there was not a single app in Hebrew. Even not for their health clinic or for the National Insurance Institute of Israel. Here we may think of how apps that are produced by formal institutions are in fact making life more difficult for those who cannot use them because when an app exists, there is an expectation that everyone will download and use it. However, when a large language digital and language literacy gap exists like in al-Quds, this does not happen. The ethnography also revealed more subtle aspects of digital illiteracy including the anxiety about whether usage conforms to social norms. For example, Aya (62) talks about the embarrassing things that can happen as a result of using the phone incorrectly:

"If you know how to use it \{the smartphone\}, it is true that there is a lot of good in it. This phone is a blessing from God, but most people do not know how to use it in a good way, so they use it to do bad stuff. Therefore, some people prefer the old 'dumb' phone."

The community in Dar al-Hawa is considered a conservative one. It is not unheard of for some members of this community to use smartphones for abusive purposes that include discrediting or shaming other people. Women, in particular, see negative effects of smartphone adoption as reflected in the use of a WhatsApp group by the Elderly Club in Dar al-Hawa who circulated an image of an old version of a mobile phone, praising its lack of capabilities and naming it "dumb":

"It lived with dignity 
It died with dignity

Never took a photo of a girl

And did not record any embarrassing situations (scandals)

And it did not carry music".

To summarize, the adoption of smartphones by older people in Dar al-Hawa is multifaceted including factors such as new forms of digital illiteracy which gives rise to expressions of ambivalence and conservatism when thinking of the smartphone situated in users' social, political, linguistic, and cultural contexts (Gordon, Al Zidjaly \& Tovares, 2017).

\section{References}

Bitman, N., \& John, N. A. (2019). Deaf and hard of hearing smartphone users: intersectionality and the penetration of ableist communication norms. Journal of Computer-Mediated Communication, 24(2), 56-72.

Geertz, C. (1974). " From the native's point of view": On the nature of anthropological understanding. Bulletin of the American Academy of Arts and Sciences, 26-45.

Gordon, C., Al Zidjaly, N., \& Tovares, A. V. (2017). Mobile phones as cultural tools for identity construction among college students in Oman, Ukraine, and the US. Discourse, Context \& Media, 17, 9-19.

Lev-On, A., Brainin, E., Abu-Kishk, H., Zilberstein, T., Steinfeld, N., Naim, S. (2019) Narrowing the gap: Characterization of participants, short- and long-term effects of participation in LEHAVA program (Hebrew).

Madianou, M., \& Miller, D. (2013). Polymedia: Towards a new theory of digital media in interpersonal communication. International Journal of Cultural Studies, 16(2), 169-187.

Palestinian Central Bureau of Statistics report, 2015. Retrieved from: https://www.thisweekinpalestine.com/wp-content/uploads/2016/09/Palestiniansin-the-Diaspora.pdf

Van Dijck, J. (2013). The culture of connectivity: A critical history of social media. Oxford University Press. 


\title{
A THEORY OF A THEORY OF THE SMARTPHONE
}

\author{
Daniel Miller \\ University College London
}

What should be the role of theory in social science? This paper begins with the argument that we need a new theory of theory, because currently theory has become a fetish, rather than an aid to social science. To exemplify an alternative use of theory it then discusses the way we have developed theories of the smartphone drawing on two 16-month ethnographies of smartphone use amongst older people in Ireland, one in a small town which we have given the name Cuan, and the other by Pauline Garvey in a district of Dublin that we have called Thornhill. The Irish materials are in turn compared with eight other fieldsites in al-Quds, Kampala, Milan, Santiago, Sao Paulo, Shanghai, Yaoundé and two sites in Japan.

The philosophical foundations for this critique of theory come mainly from Hegel's Philosophy of Right (1820/1991), but also there is at least an analogy with Wittgenstein's critique of philosophy when, in repudiation of the way he had been incorporated into formal theory by Bertrand Russell, he argued for a humbling of philosophy and theory in the face of the creativity, diversity and muddy virtues of natural language (Ree, 2019, Wittgenstein, 1922/1961:1953/1974).

Theory has become a fetish as it has shifted from a means to an end, into an end in itself. In earlier social science, the role of theory was to provide understanding, clarity and explanation (e.g. Geertz, 1973). The purpose of research was to provide original insight from substantive findings that could be better understood and explained through theory. When today, however, students are constantly told their essays do not have enough theory, we find a fetishism, especially as the main response is expected to be merely to cite established 'theorists' (e.g. Castells, 2010; McQuail, 2010). Instead of being the handmaiden to understanding the substantive world, the world is there to be exploited with the ultimate goal of paying obeisance to the deified theory. As Wacquant (2018) notes 'Bourdieu $(1988,2003)$ is frequently misread as a "theorist" when he was a dogged detractor of "conspicuous theorising." He construed theory not as the haughty master but as the humble servant of empirical inquiry, and he never advanced the one but through developing the other.' Bourdieu (1988) in Homo Academicus went further in exposing the self-interest of academics in seeking theory with its linguistic field of legitimation such as - brilliant vs. rigorous, superficial vs. deep. 
These points will be considered in relation to ASSA - a comparative ERC research project on ageing with smartphones. A major advantage of this study is that mostly up until now smartphones have been viewed as largely a youth technology. Yet we were able to complete 16 months of ethnography on the use and consequences of smartphones with older people - a population in Ireland that were mainly in their sixties and seventies. This releases the smartphone from its earlier connotations and allows us to theorize the smartphone more broadly. The intention is to avoid contemporary theory making which tends to involve a series of abstractions and generalizations geared to serve established theoretical debates, that were sundered from the initial context.

The theories that are developed in The Global Smartphone include those which are more orientated to understanding the device itself. These include our concepts of 'screen ecology', 'social ecology', 'perpetual opportunism' and 'the control hub'. Others take their point of departure more from the consequences of smartphones for the populations we studied, for example, 'the transportal home', 'beyond anthropomorphism, 'care transcending distance' or 'the relational phone'.

Each of these ideas may help to visualize, understand and explain what people do with their smartphones and why. The problem of contemporary theorising is that where this subsumes Kampala and Yaoundé in alongside Sao Paulo and Milan there is a danger of creating neo-imperial homogenisations based on citing de-contextualised critiques. The Global Smartphone describes an alternative path to theory development, which avoids these betrayals of either substance or original insight. This path remains thoroughly grounded in ethnographic materials. The way in which theory retains its grounding in ethnographic analysis is indicated by the three other papers that are being presented within this session. The first is the way 'the transportal home is explored through the presentation of ethnographic material from Japan much of which concerns quite specific contexts and consequences that pertain only to Japan. Similarly, in another the theory of 'care transcending distance is discussed through many very specific issues that derive from the author's work in Uganda. One of the main issues that links many parts of The Global Smartphone are concerned with 'contradiction and ambivalence'. The other paper in this session is deeply concerned with issues that give rise to ambivalence, but although this is true of all the fieldsites the paper makes clear that this corresponds also to certain particular issues for the Palestinian population of alQuds.

In this paper the main exemplification of this theory of theory is through grounding the same perspectives in our Irish fieldwork. Each of these generalised propositions can be linked to the particular way they are manifested in Cuan and Thornhill as in some sense 'Irish' (Inglis 2014). For example, Beyond Anthropomorphism argues for a critique of robotics as the more superficial encounter, in favor of a different kind of anthropomorphic intimacy and expressive combination of person and device. This is illustrated both through individuals in these Irish fieldsites, but also by issues of gender and other cultural orders that could be considered in some sense 'Irish'. The concept is 
directed to the unprecedented nature of intimacy between device and persons that thereby explores the issue of 'Life' - the topic of this year's conference - arguing not for life with machines, but a conceptualisation of life that acknowledges the smartphone as an aspect of persons.

The intention is to develop theory that could help us to understand smartphones wherever they are found, but which remains grounded in the specifics of each and every population and their differences from any other.

\section{References}

Bourdieu, P. (1988). Homo Academicus. Cambridge: Polity

Bourdieu, P. (2003). Participant Objectivation. Journal of the Royal Anthropological Institute 9 281-294

Castells, M. (2010) The Rise of the Network Society. Oxford: Wiley

Garvey, P. \& Miller. D. (forthcoming). Ageing with Smartphones in Ireland. London: UCL Press

Geertz. C. (1973). The Interpretation of Culture. New York: Basic Books

Hegel, G. (1991). Elements of The Philosophy of Right. Cambridge: Cambridge University Press

Inglis, T. Ed. (2014). Are the Irish Different? Manchester University PressMcQuail, D. (2010) Mass Communication Theory: An Introduction. London:Sage

Ree, J. (2019). The Young Man One Hopes For. London Review of Books, November

Wacquant, L. (2018) Four transversal principles for putting Bourdieu to work. Anthropological Theory 18(1): 3-17.

Wittgenstein, L. (1961). Tractatus Logico-Philosophicus. London: Routledge

Wittgenstein, L. (1974). Philosophical Investigations. Oxford: Blackwell 